\title{
Policy on the management of competing interest by The British Journal of Family Planning (BJFP)
}

1. Ethical publishing requires that readers are aware of competing interests of contributors to the Journal, including article, review, letter, peer review or editorial input.

2. The credibility of the Journal depends in part on how competing interest is handled during writing, peer review and editorial decision making.

3. We endorse the statement on conflict of interests in the Uniform Requirements: 'Conflict of interest for a given manuscript exists when a participant in the peer review and publication process - author, reviewer or editor - has ties to activities that could inappropriately influence his or her judgement, whether or not judgement is in fact affected'.

4. 'Competing interests' is the preferred term at BJFP because if avoids any implication of wrongdoing and may encourage greater co-operation in reporting interests.

5. We apply a broad definition of competing interests. While the most important competing interest is financial, there are other forms that we also want to know about.

6. Competing interests can inappropriately influence an author without the author being aware of the influence.

7. Definition of competing interests adopted by BJFP:

A situation of competing interests exists if the validity of a contribution to the Journal (article, review, letter, peer review or editorial input) could be influenced by an author's/editor's/reviewer's interest, whether or not judgement is, in fact, affected. Competing interests may be personal, commercial, political, religious beliefs, academic or financial. 'Financial' interests may include employment, research funding, stock or share ownership, payment for lectures or travel, consultancies and company support for staff.

8. We will not reject a paper simply because of the author's competing interests, but we will publish statements on such interests.

9. Authors of research articles, reviews, editorials and letters are asked to complete a declaration form on competing interests and financial support.

10. All of the authors are asked to sign the record of competing interests.

11. Authors are asked to complete the declaration form for all possible competing interests.

12. Contributions will not be published without a completed declaration.

13. A similar declaration will be requested from peer reviewers and members of the Editorial Advisory Board. Reviewers / Editorial Advisory Board members will be asked to disqualify / exclude themselves if they have a major competing interest.

14. We will avoid having an editorial written by somebody with a major conflict of interest, and declare the competing interest in other cases. This will be stated in the commissioning letter.

15. All contributors are encouraged to report all possible competing interests. 'If in doubt, disclose'.

16. If there is any doubt in interpreting the policy, the Honorary Editor will advise.

17. Competing interests that occurred more than 5 years earlier do not have to be declared.

18. The Honorary Editor decides if a competing interest exists and whether it needs to be stated in the article. Trivial competing interests do not have to appear in print. Sometimes there will be many stated competing interests - the Honorary Editor will decide what should be included.

19. The statement on competing interests and financial support will appear immediately after the text and before references.

20. The Honorary Editor will require authors to describe the role of outside sources of project support, if any, in study design; in the collection, analysis and interpretation of data, and in the writing of the report. If the supporting source had no such involvement, the authors should so state.

21. A competing interest will be considered sufficient to prevent publication for review articles and editorials only, and then only when the competing interest is major.

22. Failure to declare a competing interest is unethical and considered professional misconduct when done intentionally.

23. The Honorary Editor may respond with a letter of explanation, a letter of reprimand or a formal letter to the relevant head of institution or funding body.

24. Failure to disclose a major competing interest will be corrected in a subsequent issue. 